\title{
The Requirement of Fatty Acids by Pityrosporum ovale
}

\author{
By M. SHIFRINE AND A. G. MARR \\ Department of Avian Medicine and Department of Bacteriology, \\ University of California, Davis, California, U.S.A.
}

(Received 29 January 1963)

\begin{abstract}
SUMMARY
Fatty acids are required for the growth of Pityrosporum ovale (Bizzozero) Castellani et Chalmers; myristate or palmitate satisfies this requirement. Oleate increases the crop of organism in a medium containing limiting concentrations of myristate or palmitate. When $\left[1-{ }^{14} \mathrm{C}\right]$-myristate was added to the medium the cells of $\boldsymbol{P}$. ovale contained myristate, palmitate, stearate, oleate and linoleate with approximately the same molar specific radioactivity as myristate. Thus $\boldsymbol{P}$. ovale can synthesize both saturated and unsaturated fatty acids of higher molecular weight from myristate.
\end{abstract}

\section{INTREDUCTION}

Pityrosporum ovale does not grow in conventional complex media without added fats. Ota \& Huang (1933) supplemented their medium with butter or lecithin to obtain growth of this organism. Benham (1939) found that ether extracts of lanolin or butter supported good growth of $P$. ovale, and later (1941) showed that the organism would not grow in a defined medium without added fat; addition to the medium of 'oleic acid' of undefined purity permitted growth.

\section{METHODS}

Organism. The strain of Pityrosporum ovale (Bizzozero) Castellani et Chalmers used in our work was obtained from the Centraalbureau voor Schimmelcultures (Delft); it had been originally isolated by Benham (New York) from scales of human scalp. The description and historical survey of this yeast were given by Lodder \& Kreger van Rij (1952).

Cultivation. The stock culture of Pityrosporum ovale was maintained on slopes of the following composition (all quantities/100 ml.): yeast autolysate (Albimi), 1 g.; Proteose-Peptone (Difco), 1 g.; agar (Difco), 2 g.; oleic acid (C.P., Fisher Sci. Co.), $\mathbf{0} \cdot \mathbf{1}$ g., and D-glucose, $1 \mathrm{~g}$. A defined medium (Table 1) was used to determine the requirement for fatty acids. The medium was adjusted to $\mathrm{pH} 6.5$, and $5 \cdot 0 \mathrm{ml}$. portions were dispensed in $25 \mathrm{ml}$. micro-Fernbach flasks. The flasks were inoculated with $0.05 \mathrm{ml}$. of a suspension in saline (optical density, see below, about 0.5 ) of cells from a slant. The cultures were incubated in a humidified chamber at $37^{\circ}$ (Hutner, Cury \& Baker, 1958). After incubation for 6 days the optical density of the culture was measured with a spectrophotometer (Bausch \& Lomb Spectronic 20) at $640 \mathrm{~m} \mu$.

Fatty acids. Caproic, caprylic, capric, myristic, palmitic, stearic, oleic, linoleic, and linolenic acids were purchased from California Corporation for Biochemical Research (Los Angeles); lauric acid was obtained from the Eastman Kodak Co. 
(Rochester); all were estimated $>95 \%$ pure by gas-liquid chromatography. Oleic acid, C.P. (referred to in this paper as crude oleic acid) was bought from the Fisher Scientific Co. (Chicago). Radioactive myristic and stearic acids were bought from New England Nuclear (Boston).

Table 1. Basal medium for the growth of Pityrosporum ovale

\begin{tabular}{lc}
\multicolumn{1}{c}{ Compound } & (g./100 ml.) \\
$\mathrm{NH}_{4} \mathrm{H}_{2} \mathrm{PO}_{4}$ & $0 \cdot 2$ \\
$\mathrm{MgSO}_{4} \cdot 7 \mathrm{H}_{2} \mathrm{O}$ & $0 \cdot 05$ \\
$\mathrm{KH}_{2} \mathrm{PO}_{4}$ & $0 \cdot 1$ \\
L-Asparagine & $0 \cdot 25$ \\
D-Glucose & $1 \cdot 0$
\end{tabular}

\begin{tabular}{lc}
\multicolumn{1}{c}{ Compound } & $(\mu \mathrm{g} . / 100 \mathrm{ml})$. \\
$\mathrm{H}_{3} \mathrm{BO}_{3}$ & 50 \\
$\mathrm{CuSO}_{4} \cdot 5 \mathrm{H}_{2} \mathrm{O}$ & 4 \\
$\mathrm{KI}$ & 10 \\
$\mathrm{FeCl}_{3} \cdot 6 \mathrm{H}_{2} \mathrm{O}$ & 20 \\
$\mathrm{MnSO}_{4} \cdot \mathrm{H}_{2} \mathrm{O}$ & 40 \\
$\left(\mathrm{NH}_{4}\right)_{2} \mathrm{MoO}_{4} \cdot 2 \mathrm{H}_{2} \mathrm{O}$ & 20 \\
$\mathrm{ZnSO}_{4} \cdot 2 \mathrm{H}_{2} \mathrm{O}$ & 40
\end{tabular}

Recovery of fatty acids from cells of Pityrosporum ovale. The organism was grown in $2.5 \mathrm{l}$. Fernbach flasks containing $500 \mathrm{ml}$. basal medium supplemented with appropriate fatty acids. After incubation for 2 weeks the organisms were harvested by centrifugation, washed by centrifugation three times from $0 \cdot 01 \mathrm{M}-\mathrm{NaHCO}_{3}$ and three times from distilled water, and were then lyophilized. The powder was resuspended in $2 \mathrm{~N}-\mathrm{HCl}$ and hydrolysed by heating in a sealed glass ampoule for $1 \mathrm{hr}$. at $120^{\circ}$. The fatty acids were extracted twice with two volumes of diethyl ether, the pooled extract washed with water and dried with anhydrous $\mathrm{Na}_{2} \mathrm{SO}_{4}$.

Esterification. Fatty acids were esterified at $65^{\circ}$ for $1 \mathrm{hr}$. in $5 \mathrm{ml}$. anhydrous methanol containing $\mathbf{0} \cdot 1 \mathrm{~N}-\mathrm{HCl}$. The methanol was evaporated with a stream of nitrogen to about $1 \mathrm{ml}$, and the solution diluted with 2-3 ml. water. The methyl esters were extracted twice with $5 \mathrm{ml}$. portions of light petroleum (b.p. $60-70^{\circ}$ ), the pooled extracts dried with anhydrous $\mathrm{Na}_{2} \mathrm{SO}_{4}$, the solvent evaporated and the residue dissolved in benzene for analysis by gas-liquid chromatography.

Gas-liquid chromatography. The methyl esters of fatty acids were separated by chromatography at $189^{\circ}$ on an $8 \mathrm{ft} \times 0 \cdot 25 \mathrm{in}$. column of $25 \%$ diethyleneglycolsuccinate polyester on firebrick (Wilkins Instruments, Walnut Creek, California) with helium as carrier gas. The effluent was monitored with a 4-filament katharometer, the electrical output of which was recorded with a $1 \mathrm{mV}$. recorder. The amount of each ester was estimated from the area under the recorded peak. The esters were identified by comparison of their retention volumes with the retention volumes of known methyl esters. The identity of esters of unsaturated fatty acids was confirmed by catalytic hydrogenation; the esters were hydrogenated in anhydrous methanol with a catalyst of $5 \% \mathrm{Pt}$ on charcoal (Matheson, Coleman and Bell Co., Norwood, Ohio) at room temperature and at one atmosphere pressure of $\mathbf{H}_{2}$. Individual esters were recovered by passing the appropriate portion of the effluent gas through glass wool moistened with toluene.

Assay of radioactivity. Radioactivity was estimated by scintillation counting. Samples were dissolved in $15 \mathrm{ml}$. counting fluid (toluene, $380 \mathrm{ml}$; absolute ethanol, $250 \mathrm{ml}$; dioxane, $380 \mathrm{ml}$; naphthalene, 50 g.; 2,5-diphenyloxazole, 5 g.; 1,4-bis-2(5-phenyloxazolyl)-benzene, $0 \cdot 1$ g.) and placed in $25 \mathrm{ml}$. glass vials. The samples were counted with a scintillation spectrometer (Packard Instrument Co., La Grange, Illinois). 
Peroxidation of oleic acid. Oleic acid was oxidized to dihydroxystearic acid with performic acid according to the method of Swern, Billen, Findley \& Scanlan (1945). A sample containing $100 \mathrm{mg}$. or less of oleic acid was allowed to react with $1 \mathrm{ml}$. formic acid and $0 \cdot 1 \mathrm{ml}$. of $30 \% \mathrm{H}_{2} \mathrm{O}_{2}$ at $40^{\circ}$ for $2 \mathrm{hr}$. with occasional shaking. The reaction mixture was diluted with $5 \mathrm{ml}$. water, extracted three times with $5 \mathrm{ml}$. portions of diethyl ether, the extracts pooled and the ether evaporated off. The product (hydroxyformoxystearic acid) was saponified in $2 \mathrm{ml} .3 \mathrm{~N}-\mathrm{NaOH}$ at $100^{\circ}$ for $30 \mathrm{~min}$. After the alkaline solution had cooled, it was acidified with $4 \mathrm{ml}$. $3 \mathrm{~N}-\mathrm{HCl}$ and extracted three times with $5 \mathrm{ml}$. portions of diethyl ether. The ether extract contained dihydroxystearic acid which was identified by a comparison of the infrared spectrum of the product with the spectrum of authentic 9,10-dihydroxystearic acid.

Chromatographic separation of dihydroxystearic acid. In the experiments designed to determine the conversion of radioactive stearic acid to oleic acid it was necessary to separate oleic acid from the radioactive stearic acid. Resolution of methyl stearate and methyl oleate by gas-liquid chromatography was inadequate. The problem was solved by the prior conversion of oleic acid to dihydroxystearic acid, followed by the separation of dihydroxystearic acid from the non-polar fatty acids by partition chromatography. A sample of the mixed fatty acids was peroxidized and the products were transferred to a $3 \mathrm{~g}$. column of silicic acid (Mallinkrodt). The non-polar fatty acids were eluted with $30 \mathrm{ml} .10 \%(\mathrm{v} / \mathrm{v})$ diethyl ether in light petroleum. The column was washed with $30 \mathrm{ml}$. diethyl ether to remove residual non-polar acids. The dihydroxy acid was eluted with $\mathbf{3 0} \mathrm{ml}$. methanol.

The efficiency of the method was tested by separating a mixture of $50 \mathrm{mg}$. each of stearic and oleic acid, to which mixture was added a small amount of $\left[1-{ }^{14} \mathrm{C}\right]$-stearic acid. The mixture was peroxidized and chromatographed. The first fraction (stearic acid) contained 526 c.p.m.; the second fraction contained 5 c.p.m., and the third fraction (dihydroxystearic acid) 5 c.p.m.

\section{RESULTS}

\section{Response to oleate}

Pityrosporum ovale did not grow in the basal medium supplemented with pure oleic acid but did grow in basal medium supplemented with crude oleic acid or with catalytically hydrogenated crude oleic acid.

Table 2. Fatty acid composition of crude oleic acid

\begin{tabular}{lclc}
\multicolumn{1}{c}{ Fatty acid } & $\%(\mathbf{w} / \mathbf{w})$ & Fatty acid & $\%(\mathbf{w} / \mathbf{w})$ \\
Myristic & $\mathbf{3 \cdot 6 1}$ & Hexadecenoic & $\mathbf{1 3 \cdot 2 0}$ \\
Tetradecenoic & $\mathbf{2 \cdot 7 3}$ & Oleic & $\mathbf{7 5 \cdot 4 8}$ \\
Palmitic & $\mathbf{4} \cdot \mathbf{9 8}$ & Linoleic & Trace
\end{tabular}

The composition of a sample of crude oleic acid was determined by gas-liquid chromatography (Table 2); oleic acid was the major constitutent and the sample also contained considerable amounts of myristic and palmitic acids and the corresponding mono-unsaturated fatty acids, tetradecenoic and hexadecenoic acids. 


\section{Response to saturated fatty acids}

Since the response to crude oleate was not affected by hydrogenation, it appeared that the saturated fatty acids, myristic and palmitic, were responsible for the growth of Pityrosporum ovale in basal medium supplemented with crude oleic acid. This possibility of a requirement for saturated fatty acids was tested by addition to the basal medium of single saturated fatty acids with an even number of carbon atoms (Table 3). Saturated fatty acids from $\mathrm{C}_{4}$ to $\mathrm{C}_{10}$ and stearic acid did not permit growth; lauric acid $\left(\mathrm{C}_{12}\right)$ permitted some growth; myristic $\left(\mathrm{C}_{14}\right)$ and palmitic $\left(\mathrm{C}_{16}\right)$ gave good growth.

Table 3. Effect of additions of single fatty acids to basal medium on the growth of Pityrosporum ovale

$\begin{array}{clcc}\text { Fatty acid added } & \overbrace{1}^{\begin{array}{c}\text { Concentration of added fatty acid } \\ \text { (mg./100 ml.) }\end{array}} \begin{array}{c}5 \\ \text { Optical density reading }(640 \mathrm{~m} \mu)\end{array} \\ \text { Butyric } & 0 & 0 & 0 \\ \text { Caproic } & 0 & 0 & 0 \\ \text { Caprylic } & 0 & 0 & 0 \\ \text { Capric } & 0 & 0 & 0 \\ \text { Lauric } & 0 \cdot 04 & 0 \cdot 12 & 0 \cdot 15 \\ \text { Myristic } & 0 \cdot 12 & 0 \cdot 31 & 0.40 \\ \text { Palmitic } & 0 \cdot 15 & 0 \cdot 30 & 0.40 \\ \text { Stearic } & 0.03 & 0 \cdot 05 & 0.08\end{array}$

Sparing effect of oleic acid

The efficacy of palmitic and myristic acids in permitting growth of Pityrosporum ovale when added to the basal medium explained in part the response of the organism to the crude oleic acid, which contained both myristic and palmitic acids. However, the response to the crude oleic acid was greater than expected from its content of myristic and palmitic acids. Various mixtures of myristic and palmitic acids added to the basal medium did not give greater than an additive increase in the yield of $\boldsymbol{P}$. ovale. It appeared that oleic acid might be sparing the requirement for saturated fatty acids. Figure 1 shows the effect of adding pure oleic acid $(5 \mathrm{mg} . / 100 \mathrm{ml}$.) to basal medium containing different concentrations of myristic acid. Oleic acid significantly increased the crop of $\boldsymbol{P}$. ovale in basal medium containing limiting concentrations of myristic acid. A similar increase in crop was observed when oleic acid was added to basal medium containing limiting concentrations of palmitic acid.

If stearic acid is an effective precursor of oleic acid, stearic acid, like oleic acid, should spare the requirement for myristic acid. Supplementation with stearic acid of a medium containing a limiting concentration of myristic acid gave equivocal results; in some tests stearic acid did not spare the requirement for myristic acid, while in other tests stearic acid increased the yield of organism. Linoleic acid did not spare the requirement for myristic acid. 
Fatty acid composition of the lipids of Pityrosporum ovale

Pityrosporum ovale harvested from basal medium supplemented with myristic or palmitic acids was analysed for fatty acids by gas-liquid chromatography. The organisms grown in basal medium supplemented with myristic acid contained

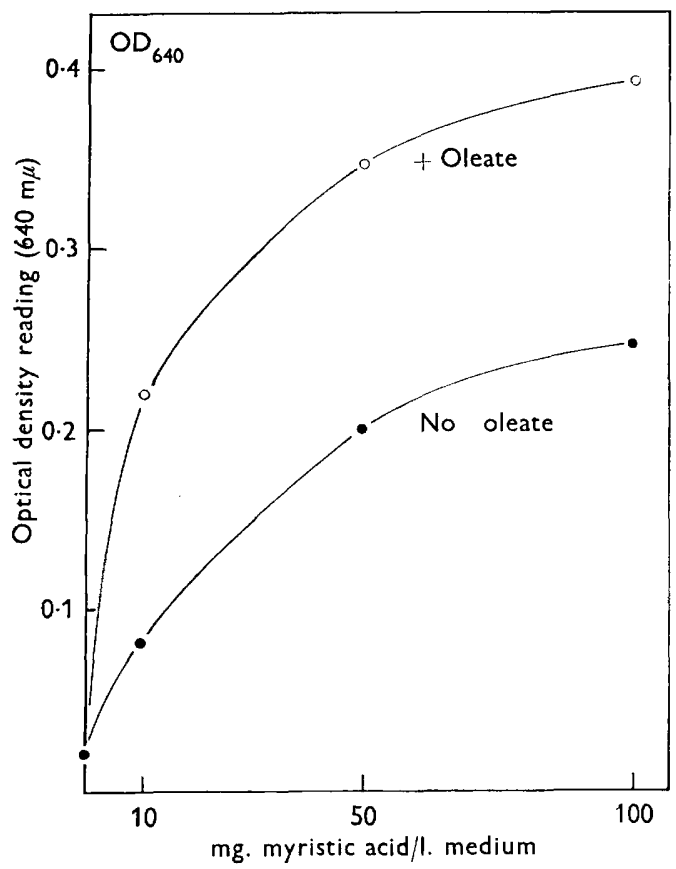

Fig. 1. The effect of oleic acid $(5 \mathrm{mg} . / 100 \mathrm{ml}$.) on growth of Pityrosporum ovale in basal medium containing different concentrations of myristic acid.

Table 4. Composition of fatty acids from Pityrosporum ovale grown in basal medium supplemented with myristic acid or palmitic acid

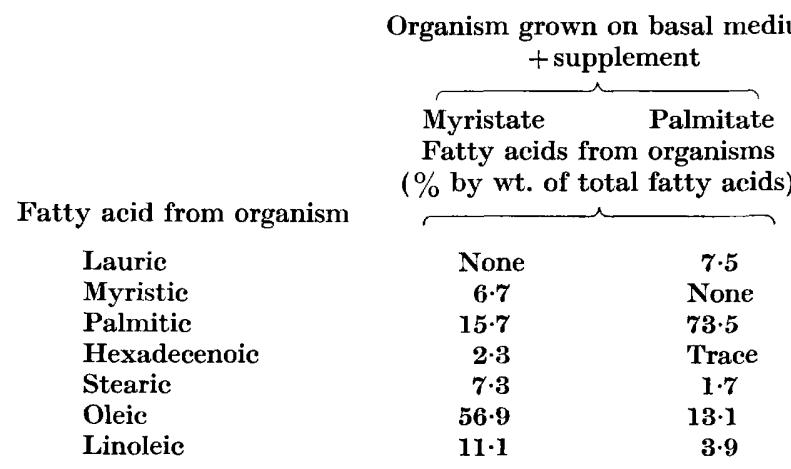

myristic, palmitic, hexadecenoic, stearic, octadecenoic (oleic), and octadecadienoic (linoleic) acids (Table 4), of which oleic acid was the principal one. The organisms grown in basal medium supplemented with palmitic acid differed in that they did 
not contain myristic acid but did contain a considerable amount of lauric acid. Palmitic acid rather than oleic acid appeared to be the principal fatty acid in these organisms. The variation in proportion of different fatty acids from organisms grown with the same supplement was not sufficient to change the order of abundance of different fatty acids. Thus the change in composition of fatty acids from organisms grown with different supplements is significant.

Table 5. Radioactivity of fatty acids of Pityrosporum ovale grown in basal medium supplemented with $\left[1-{ }^{14} \mathrm{C}\right]$ myristic acid

$\begin{array}{lcc} & & \begin{array}{c}\text { Percentage } \\ \text { of the specific } \\ \text { activity of } \\ \text { added } \\ \text { myristic }\end{array} \\ \text { Fatty acid } & \text { c.p.m. } / \mu \text { mole } & \text { acid } \\ \text { Myristic } & 13,200 & 72 \\ \begin{array}{l}\text { Palmitic and } \\ \text { tetradecenoic }\end{array} & 11,000 & 60 \\ \text { Stearic } & 15,600 & 85 \\ \text { Oleic } & \mathbf{8 , 2 0 0} & \mathbf{4 5} \\ \text { Linoleic } & \mathbf{1 2 , 2 0 0} & \mathbf{6 8}\end{array}$

Synthesis of higher fatty acids from myristic acid

The results of the nutritional experiments together with the analyses of the organisms for fatty acids suggested that Pityrosporum ovale is unable to synthesize myristic acid or higher fatty acids. The possibility that higher fatty acids are synthesized from myristic acid was tested by using radioactive myristic acid. $\boldsymbol{P}$. ovale was grown in basal medium supplemented with $\left[1-{ }^{14} \mathrm{C}\right]$-myristic acid and with sufficient acetate to dilute the label of any radioactive acetic acid produced from the metabolism of myristic acid. After hydrolysis of the organisms, the fatty acids were extracted, esterified, and separated by gas-liquid chromatography. The molar radioactivities of the fatty acids (Table 5) are computed on the assumption of complete recovery of each ester from the effluent. Since recovery was not complete the molar specific activities of all of the fatty acids except oleic acid must be considered as essentially the same as the molar specific activity of the $\left[1^{14} \mathrm{C}\right]$-myristic acid added to the basal medium. Perhaps oleic acid is formed by a separate route as well as from myristic acid. Thus, most if not all of the higher fatty acids are synthesized from myristic acid.

\section{Conversion of stearic acid to oleic acid}

Since stearic acid gave a slight but significant sparing of the requirement of Pityrosporum ovale for lower fatty acids it appeared likely that stearic acid could serve as a precursor of oleic acid as it does in Saccharomyces (Bloomfield \& Bloch, 1960). This was tested by supplying a culture of $P$. ovale with radioactive stearic acid and measuring the radioactivity in oleic acid recovered from the lipids. $P$. ovale was grown in basal medium supplemented with myristic acid $(5 \mathrm{mg} . / 100 \mathrm{ml}$.) and $2 \mu \mathrm{c}$ of $\left[1{ }^{14} \mathrm{C}\right]$-stearic acid $(0.74 \mathrm{mg} . / 100 \mathrm{ml}$.). The organisms were harvested, washed, hydrolysed, and the fatty acids extracted from the hydrolysate. One 
portion of the hydrolysate was esterified and the methyl esters analysed by gasliquid chromatography (Table 6). Another portion was peroxidized, the non-polar fatty acids in the peroxidized sample separated from dihydroxystearic acid by chromatography on silicic acid and the radioactivities of the fractions eluted from the column were determined (Table 6). It was assumed that all of the radioactivity in the fraction containing non-polar acids was contained in the stearic acid.

The results in Table 6 show a significant difference in the composition of fatty acids when stearic acid was added to the medium (compare with the first column in Table 5). Stearic acid appeared to be the principal $\mathrm{C}_{18}$ fatty acid; oleic acid was no longer a predominant fatty acid. Another difference in the composition was the presence of two unidentified components not detected in previous analyses (compare with Table 4).

Table 6. Composition and radioactivity of fatty acids from Pityrosporum ovale grown in basal medium $+\left[1^{-14} \mathrm{C}\right]$-stearic acid

$\begin{array}{cccc}\text { Fatty acid in organism } & \begin{array}{c}\text { Percentage } \\ \text { by weight } \\ \text { of total } \\ \text { fatty acids }\end{array} & \begin{array}{c}\text { Radioactivity } \\ \text { (c.p.m.) }\end{array} & \begin{array}{c}\text { Relative } \\ \text { specific } \\ \text { activity }\end{array} \\ \text { Lauric } & \mathbf{1 4 \cdot 7} & - & - \\ \text { Myristic } & \mathbf{2 3 \cdot 1} & - & - \\ \text { Palmitic } & \mathbf{1 5 \cdot 7} & - & - \\ \text { Stearic } & \mathbf{3 0 \cdot 0} & \mathbf{1 0 , 8 0 0} & \mathbf{1 2 1} \\ \text { Oleic } & \mathbf{3 \cdot 7} & \mathbf{2 , 8 0 0 ^ { * }} & \mathbf{2 5 4} \\ \text { Linoleic } & \text { Trace } & - & - \\ \text { Unidentified I } \dagger & 6 \cdot 7 & - & - \\ \text { Unidentified II } & 6 \cdot 1 & - & -\end{array}$

* The sample of dihydroxystearic acid obtained by peroxidation was purified twice by chromatography before assay for radioactivity.

$\dagger$ Retention volume relative to methyl palmitate was $\mathbf{0 . 8 0}$.

Retention volume relative to methyl palmitate was $1 \cdot 32$.

The results are in accord with a conversion of stearic acid to oleic acid. At the time of harvest the specific radioactivity of stearic acid was lower than the specific radioactivity of oleic acid. This may have resulted from a continuous dilution of the radioactive stearic acid resulting from synthesis of stearic acid from myristic acid during growth of the culture.

\section{DISCUSSION}

Our results do not confirm that Pityrosporum ovale requires added oleic acid for growth (Benham, 1941). Addition of oleic acid alone under our conditions did not permit growth in a defined medium; however, oleic acid did increase the crop of organisms in a medium containing limiting concentrations of either myristic or palmitic acid. Perhaps the results of Benham can be attributed to impurities of saturated fatty acids in the sample of oleic acid used, comparable to the impurities we found in a commercial sample of oleic acid. Both nutritional and tracer experiments suggest that the requirement for fatty acids in $\boldsymbol{P}$. ovale results from an inability to synthesize myristic acid. When $\boldsymbol{P}$. ovale was grown on basal medium with $\left[1^{14} \mathrm{C}\right]$-myristic acid, the myristic acid of the organisms had essentially the same specific radioactivity as the myristic acid added to the medium. Furthermore, 
the higher fatty acids isolated from the organisms (palmitic, stearic, oleic, linoleic acids) also had nearly the same molar radioactivity as had the myristic acid. Thus, the higher fatty acids appear to have been synthesized by elongation of the carbon chain of myristic acid. Myristic acid itself is not an essential nutrient for $\boldsymbol{P}$. ovale. Organisms grown in basal medium + palmitic acid did not contain detectable amounts of myristic acid. Organisms grown with palmitic acid contained rather large amounts of lauric acid which was not present in organisms grown with myristic acid.

Stearic acid either did not spare the requirement for lower molecular weight saturated fatty acids or was less effective than oleic acid in sparing this requirement. From these results it appeared unlikely that the oxidation of stearic acid was a major pathway contributing to the synthesis of oleic acid. However, the high specific radioactivity of oleic acid from organisms grown in a medium containing radioactive stearic acid is in agreement with the formation of oleic acid from the oxidation of stearic acid, a major pathway in Saccharomyces (Bloomfield \& Bloch, 1960). The analysis of the fatty acids from Pityrosporum ovale grown in medium containing stearic acid + myristic acid showed an abnormally low content of oleic acid and the presence of substantial amounts of previously undetected fatty acids. This suggests an explanation for the failure of stearic acid to spare as effectively as did oleic acid the requirement for myristic acid. The supplementation of the medium with stearic acid apparently inhibited the synthesis of oleic acid and perhaps perturbed the synthesis of other fatty acids, possibly by interfering with the normal mechanism of control.

Pityrosporum ovale is so far unique among micro-organisms in its requirement of $\mathrm{C}_{\mathbf{1 4}}$ or $\mathrm{C}_{16}$ saturated fatty acids, which requirement results from a block in the synthesis of myristic acid. All of the higher saturated fatty acids can be formed by chainelongation, and oleic acid is formed, presumably, by oxidation of stearic acid. The inability of $\boldsymbol{P}$. ovale to synthesize higher fatty acids from acetate permits a study of the conversion of the higher fatty acids without the complication of de novo synthesis.

This work was supported by grants-in-aid G-9860 and G-23767 from the National Science Foundation (U.S.A.) and E-1726 from the National Institutes of Health (U.S.A.). We wish to thank Mrs Judith Corbett for her assistance.

\section{REFERENCES}

Benham, R. W. (1939). Cultural characteristics of Pityrosporum ovale-a lipophylic fungus. J. invest. Derm. 2, 187.

Benham, R. W. (1941). Cultural characteristics of Pityrosporum ovale-a lipophylic fungus. Nutrient and growth requirements. Proc. Soc. exp. Biol., N.Y. 46, 176.

Bloomfield, D. K. \& Bloch, K. (1960). The formation of $\Delta^{9}$-unsaturated fatty acids. J. biol. Chem. 235, 337.

Hutner, S. H., Cury, A. \& Baker, H. (1958). Microbiological assays. Analyt. Chem. 30, 849.

Lodder, J. \& Kreger-van RiJ, N. J. W. (1952). The Yeasts. A Taxonomic Study. Amsterdam: North Holland Publ. Co.

Ota, M. \& Huang, P. T. (1933). Sur les champignons du genre Pityrosporum Sabouraud. Ann. Parasit. hum. comp. 11, 49.

Swern, D., Billen, G. N., Findley, T. W. \& Scanlan, J. T. (1945). Hydroxylation of monounsaturated fatty materials with hydrogen peroxide. J. Amer. chem. Soc. 67, 1786. 